\title{
Las relaciones húngaro-mexicanas entre 1990 y 2020 . Una mirada desde Hungría ${ }^{1}$
}

Hungarian-Mexican Relations between 1990 and 2020. A Perspective from Hungary Mónika, Szente-Varga'2; Agustín, Sánchez Andrés ${ }^{3}$

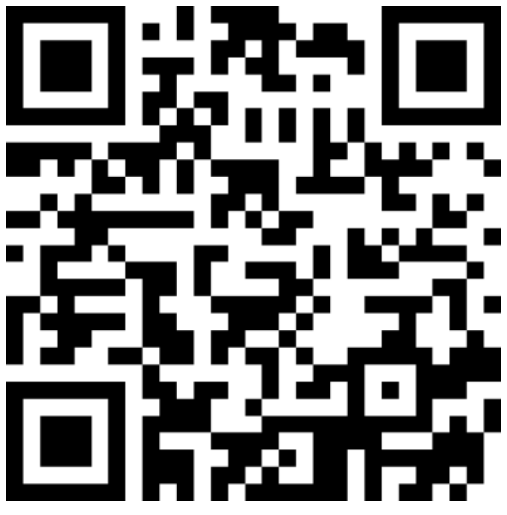

Fecha de recibido: $30-02-2021$

Fecha de aceptado: 22-04-2021

\section{(c)) BY-NC-ND}

Esta obra está bajo una licencia de Creative Commons Reconocimiento-NoComercialSinObraDerivada 4.0 Internacional

\begin{abstract}
RESUMEN
El presente artículo es resultado de una investigación que tuvo por objetivo los nexos oficiales entre Hungría y México en el período entre 1990 y 2020. El texto cuenta con una estructura cronológica y se divide en dos épocas, siendo el punto de inflexión la adhesión de Hungría a la Unión Europea en 2004. Se han utilizado métodos mixtos para el estudio, principalmente cualitativo, y en menor medida cuantitativo. Se observó que, en los veinte años siguientes al cambio de régimen en Hungría, América Latina fue relegada a la periferia de su política exterior debido a las limitaciones presupuestarias y a la necesidad de concentrarse en el proceso de adhesión a la Unión Europea. El número de las embajadas húngaras en la región fue reducido de once a cuatro. La entrada de Hungría a la UE tuvo el potencial de provocar cambios importantes, porque así el país se hizo partícipe de los acuerdos internacionales ya existentes de la organización con México y, en general, con América Latina. Ello proporcionó a Hungría la posibilidad de aprovechar dichos compromisos para potenciar las relaciones con México. Se concluye que las oportunidades en las relaciones no han sido suficientemente aprovechadas por motivos tanto internos como internacionales.
\end{abstract}

Palabras claves: Hungría, México, Unión Europea, Política exterior, Relaciones internacionales.

\begin{abstract}
This article is the result of an investigation whose aim is to study the interstate relations between Hungary and Mexico between 1990 and the present, 2020. The text has a chronological structure and is divided into two parts, the watershed being the accession of Hungary to the European Union in 2004. Mixed methods have been used: principally qualitative (discourse analysis) and in a minor portion quantitative one (statistical data). It was found that in the 20 years following the change of regime in Hungary, Latin America has been relegated to the periphery of its foreign policy, for the lack of financial resources and for concentrating on the process of accession to the EU. The number of Hungarian embassies in the region was reduced from eleven to four. The EU membership of Hungary had the potential of resulting in important changes, because this way the country became part of the already existing international agreements the organization had concluded with Mexico, and in general with Latin America. Besides, it obtained the possibility of actively forming these links. It is concluded that the opportunities present in the relations have not been sufficiently taken advantage of, the reasons being both internal and international.
\end{abstract}

Keywords: Hungary, Mexico, European Union, Foreign policy, International relations.

Cómo referenciar este artículo:

Szente-Varga., M., \& Sánchez Andrés., A. (2022). Las relaciones húngaro-mexicanas entre 1990 y 2020. Una mirada desde Hungría. Revista Política, Globalidad y Ciudadanía, 8(15), 1-26. https://doi.org/10.29105/pgc8.15-1

\footnotetext{
${ }^{1}$ Este artículo pertenece al proyecto de investigación Relaciones entre México y Hungría, siglos XIX-XXI, respaldado por la Universidad Nacional de Servicio Público y la Universidad Michoacana de San Nicolás de Hidalgo entre enero de 2019 y diciembre de 2020.

${ }^{2}$ Universidad Nacional de Servicio Público, Hungría. Doctora en Historia por la Universidad de Szeged, profesora titular en el Departamento de Relaciones Internacionales y Diplomacia de la Universidad Nacional de Servicio Público en Budapest, Hungría. Correo electrónico: Szente-Varga.Monika@uni-nke.hu. Orcid: https://orcid.org/0000-0001-7403-6960.

${ }^{3}$ Universidad Michoacana de San Nicolás de Hidalgo, México. Doctor en Geografía e Historia por la Universidad Complutense de Madrid, profesorinvestigador en el Instituto de Investigaciones Históricas de la Universidad Michoacana de San Nicolás de Hidalgo, México. Correo electrónico: asamadrid@ hotmail.com. Orcid: https://orcid.org/0000-0001-6569-5067.
}

1 Revista Política, Globalidad y Ciudadanía | Vol. 8, Núm. 15, enero - junio 2022 | ISSN 2395-8448 | http://revpoliticas.uanl.mx/ 


\section{1.- INTRODUCCIÓN}

El propósito de este ensayo es investigar los nexos oficiales entre Hungría y México en el período que media entre 1990 -momento del cambio de régimen político en Hungría-, y la actualidad, 2020. El objetivo es determinar los factores que han condicionado el bajo perfil de las relaciones entre ambos países y analizar las directrices de la política húngara hacia México, así como su evolución durante la etapa estudiada. Para ello, serán examinados tanto los lazos bilaterales húngaro-mexicanos como las relaciones multilaterales que se han desarrollado a través de la Unión Europea (UE), especialmente a partir de 2004, fecha de la adhesión húngara. No existen estudios precedentes en torno a este tema, si exceptuamos una primera aproximación en el marco más amplio de la historia de las relaciones entre Hungría y México desde el siglo XIX (Szente-Varga, 2017). Fuera de ello, disponemos únicamente de referencias generales en torno a la política exterior de la Hungría democrática (Gazdag, 2014; Gazdag \& Kiss, 2017) que no incluyen ni México, ni Latinoamérica, por tanto, principalmente fuentes primarias sirven de base a nuestra investigación.

El estudio cuenta con una estructura diacrónica y se divide en dos épocas: 1990-2004 y 20042020, siendo el punto de inflexión la adhesión de Hungría a la UE. Comienza con un análisis de las relaciones húngaro-mexicanas entre 1990 y 2004 desde un enfoque bilateral en el contexto de las alteraciones de la presencia diplomática de Hungría en América Latina, seguido por un resumen de las visitas bilaterales más destacadas en las relaciones entre México y Hungría. Llegando a 2004, hay un cambio de perspectiva y se estudian los nexos entre ambos países a través de la Unión Europea en tres subcapítulos: antecedentes, institucionalización y tratos a partir de 2004. Para terminar, volvemos al plano bilateral para estudiar las estrategias húngaras post-2004 en cuanto a comercio y asuntos exteriores, con especial énfasis sobre América Latina, y en particular, respecto al rol asignado a México en las mismas.

\section{2.- FUNDAMENTO TEÓRICO}

Este escrito pertenece al campo de la historia de las relaciones internacionales, que naturalmente incluye la historia diplomática, pero que es más amplio, ya que pretende cubrir "las interacciones de Estados, personas y culturas" (Hogan \& Paterson, 2004, p. 10). Los Estados, en este caso Hungría y México, siguen teniendo un papel clave en el análisis, pero otros actores, como las organizaciones internacionales, deben ser también tomados en cuenta. En lugar de relaciones estrictamente interestatales y bilaterales, el 
estudio también incluye enlaces multilaterales, que han crecido en importancia con la globalización. El objetivo es estudiar el desarrollo de los contactos húngaro-mexicanos a través de tres décadas (19902020), y de varios niveles de enfoque. No pretendemos escribir historias nacionales, sino que por el contrario nos centraremos en la historia de los acercamientos e interconexiones entre estas dos naciones, es decir, en una historia interconectada.

En relación a los nexos bilaterales de carácter estatal, la Secretaría de Relaciones Exteriores de México ha publicado un considerable número de volúmenes sobre las relaciones de México con otros países, sin embargo, faltan análisis sobre Europa Central / Oriental. Polonia podría ser una excepción por existir un libro de referencia (Archivo Histórico Diplomático Mexicano, 1989) que presenta una cronología y 55 documentos oficiales referentes a los nexos polaco-mexicanos, pero no se trata de una obra de análisis histórico. Por el lado europeo, el Centro de Estudios Ibero-Americanos de la Universidad de Praga inició una serie sobre las relaciones checas con el mundo hispano, editada por Josef Opatrný, en el marco de la cual tuvo lugar la publicación Las relaciones checo-mexicanas en 2011. En el caso de Hungría disponemos del libro El baúl de las nomeolvides. Relaciones húngaro-mexicanas de Mónika Szente-Varga (2017), que nos proporciona una panorámica general de dichas relaciones desde la época del Imperio Austro-húngaro hasta la actualidad. El presente artículo pertenece a este campo de investigaciones, y profundiza sobre los contactos entre Hungría y México durante los últimos treinta años.

Nexos entre Hungría y México, 1990-2004

Los últimos años del siglo XX trajeron consigo el fin del mundo bipolar. Terminaron de funcionar en 1991 las organizaciones de los países socialistas, el Pacto de Varsovia -establecido en la capital polaca en 1955 con objetivos militares- y el Consejo de Ayuda Mutua Económica (CAME), creado en 1949, de índole económica-comercial. De hecho, dejó de existir el bloque socialista en sí. El statu quo establecido tras la Segunda Guerra Mundial quedó alterado con la reunificación de Alemania (1990), la desaparición de la Unión Soviética (1991), la disolución de Checoslovaquia (1993), así como por las guerras balcánicas y el ocaso de Yugoslavia (1991-1995).

Hungría se encontró en una situación nueva, con nuevos vecinos. Dejó de tener frontera con la Unión Soviética, Checoslovaquia y Yugoslavia, por el desmembramiento de estos países, y actualmente 
colinda con Eslovaquia en el norte, Ucrania y Rumania por el este, Serbia, Croacia y Eslovenia por el sur y Austria por el oeste.

La retirada de las tropas soviéticas de Hungría (unos 50 mil soldados, 19 mil empleados civiles y 32 mil familiares) comenzó en abril de 1989 y terminó en junio de 1991 (Romsics, 1999, p. 574). El fin de ese proceso, junto con los cambios arriba descritos, significó que Hungría recuperó su soberanía y se hizo posible la formación de una nueva política exterior, mucho más autónoma. Las prioridades indicadas por József Antall, primer ministro de Hungría entre 1990 y 1993, fueron las siguientes: 1) relaciones de buena vecindad con los países fronterizos, 2) protección efectiva de las comunidades húngaras fuera del país, y 3) orientación euro-atlántica (esto es, UE y OTAN). Pronto esta última meta ganó importancia, puesto que se vio como una garantía contra una posible influencia soviética / rusa, y por tanto para la seguridad del país y de su recién recuperada independencia. La adhesión a la Unión Europea y a la OTAN se convirtieron en los principales objetivos de los gobiernos húngaros. Esto conllevó un enfoque básicamente europeísta. Las regiones del mundo fuera del viejo continente en su gran mayoría fueron relegadas a segundo plano, en parte por la nueva perspectiva, y en parte por las presiones económicas derivadas de los problemas presupuestarios del gobierno húngaro. La combinación de dichos factores trajo consigo el cierre de varias representaciones húngaras. Las situadas en América Latina resultaron muy afectadas.

\section{Contexto: América Latina y México en la política exterior húngara}

A finales de 1990 Hungría contaba con 73 embajadas en el mundo, 11 de ellas en América Latina: en Argentina, Uruguay, Brasil, Chile, Perú, Ecuador, Colombia, Venezuela, Nicaragua, Cuba y México (KM, 1990, p. 396). Los países del istmo centroamericano y del Caribe estuvieron en su mayoría cubiertos con acreditaciones paralelas, o sea en forma concurrente, desde las oficinas en la Ciudad de México (Honduras, Jamaica), en Managua (Costa Rica y Panamá) y en Caracas (Trinidad y Tobago, Barbados, República Dominicana y Granada). Hubo iniciativas para arreglar algunas conexiones pendientes, y en 1990 quedaron restablecidos los lazos entre Chile y Hungría, existentes entre 1965 y 1973, hasta el golpe; y también se creó un nuevo vínculo con Guatemala.

Diez años más tarde, funcionaban 75 embajadas húngaras en el mundo, sin embargo, esto no implicó un refuerzo de la presencia húngara en el continente americano, todo lo contrario: a finales de 2000 había solamente seis embajadas en la región, en lugar de los once originales. Hungría mantuvo 
únicamente sus sedes en Argentina, Brasil, Chile, Colombia, Cuba y México (KM, 2000, pp. 331-355). Había cerrado sus embajadas en Uruguay, Perú, Ecuador, Venezuela y Nicaragua. En el último caso los motivos políticos bien pudieron haber tenido un peso importante, puesto que las aproximaciones húngaro-nicaragüenses se habían basado en consideraciones político-ideológicas durante la guerra fría $\mathrm{y}$, con el fin del mundo bipolar, la política exterior húngara no quiso mantener lo que antes había sido obligatorio (Szente-Varga, 2018, pp. 78-86). La embajada fue primero trasladada de Managua a San José, Costa Rica, la cual fue finalmente cerrada en 1993 por problemas económicos, dejando a Hungría sin ninguna sede residente en Centroamérica. Esto trajo consigo más trabajo para la representación húngara en la Ciudad de México, que para 2000 manejaba ya las concurrencias en Guatemala, Costa Rica y Jamaica, y puesto que tanto Honduras como El Salvador habían estado cubiertos desde Costa Rica mientras funcionaba allí la embajada de Hungría, era de esperarse que dichos países también quedaran como tareas para la misma misión. El hecho de que esto siguiera aún pendiente en 2000 es una clara señal de que la política húngara no consideraba esta cuestión como urgente, pues desde el cierre de la embajada en San José pasaron años antes de que los asuntos relativos a ambos países quedaran integrados a la oficina de la Ciudad de México.

\section{Visitas bilaterales húngaro-mexicanas (1990-2004)}

La frecuencia y la importancia de los encuentros se mantuvo fluctuante en los últimos 30 años, de los cuales la primera parte vio más actividad. La época al término de la guerra fría empezó con una visita de lujo: la del economista y reconocido investigador y profesor universitario, Béla Kádár, especialista en el problema de la modernización tardía, en los procesos de crecimiento económico y en la cooperación económica internacional. Kádár había dado clases en Chile en 1970 y en la Universidad de San Marcos en Lima en 1971-72. Fue vicepresidente del Consejo Europeo de Investigaciones Sociales de América Latina (CEISAL) entre 1984 y 1992, y ocupó el cargo de ministro de relaciones económicas internacionales de Hungría entre 1990 y 1994, de hecho, se podría subrayar que fue el primero en desempeñarse como ministro de comercio de la Hungría de la posguerra fría. Fue en tal calidad que hizo una visita oficial a México en 1991 (KM, 1991, p. 51).

El 500 aniversario del encuentro de los dos mundos, 1992, marcó un hito en los contactos bilaterales, incluyendo el viaje en marzo a México de Géza Jeszenszky, ministro de Relaciones Exteriores de Hungría (después pasarían más de veinte años para que se diera una visita de la misma índole). La visita de Jeszenszky, quien fue recibido por Salinas de Gortari, sirvió para preparar la firma de diversos 
acuerdos que serían suscritos durante la visita del mandatario mexicano a Hungría, pocos meses más tarde. Ello permitió al canciller húngaro declarar a su retorno el inicio de "una nueva y prometedora etapa de las relaciones entre los dos países", y asegurar -con un exceso de optimismo- que "México dedica mucha atención a Hungría, no sólo como país en el umbral de acceder a la Comunidad Europea, sino también como la puerta hacia el Oriente" (AHGE-SREM, 1992a).

Este viaje sería seguido por la visita oficial a Hungría del presidente de México, Carlos Salinas de Gortari en julio de 1992, primera efectuada por un presidente americano a este país desde el cambio de régimen, por lo que fue seguida con enorme interés por los medios de comunicación húngaros. Le acompañaron Fernando Solana, secretario de Relaciones Exteriores y un buen número de empresarios. El presidente Salinas sostuvo negociaciones con los principales líderes húngaros del período democrático, el primer ministro, József Antall, y el presidente Árpád Göncz (KM, 1992, p. 16, 52). Su visita serviría para dar un cierto impulso a las relaciones entre ambos países, al tiempo que permitía relanzar la imagen de México en Hungría (AHGE-SREM, 1992b). Posteriormente, en 1997, el presidente Göncz efectuó una visita oficial a México como parte de su gira por América Latina, que incluyó a Brasil, Argentina y Paraguay -el presidente era entonces Juan Carlos Wasmosy, de ascendencia húngara- para terminar en México (KM, 1997, p. 116). Se entrevistó con el presidente Ernesto Zedillo -quien facilitó la alternancia política, poniendo fin a más de 70 años consecutivos de gobiernos del PRI-, así como con el jefe del gobierno de la Ciudad de México, Óscar Espinoza Villareal, quien a su vez fuera la última persona designada por mandato presidencial para este cargo, ya que sus sucesores han ocupado el puesto desde entonces mediante elección popular. La diplomacia mexicana siguió con interés la llegada de la oposición conservadora al poder, el ingreso de Hungría en la OTAN y los posibles cambios de la política exterior húngara tras el nombramiento de Viktor Orbán como primer ministro en junio de 1998 (AHGESREM, 1998). En este marco, tuvo lugar la visita a Hungría de la secretaria de Relaciones Exteriores de México, Rosario Green, quien se entrevistó con su contraparte, János Martonyi, así como con el primer ministro Orbán (KM, 1998, p. 51). En 2000, János Áder, presidente del Parlamento húngaro, estuvo de visita en Chile, Brasil y México, llegando a este último destino antes de las elecciones presidenciales de ese año. Fue recibido por Rosario Green y por Ernesto Zedillo.

El siglo XXI comenzó con los comicios que pusieron fin al régimen presidencialista de partido hegemónico en México. Después de más de siete décadas se dio un cambio, y el Partido Acción Nacional (PAN) accedió al poder. El nuevo presidente, Vicente Fox, visitó Hungría en 2004. Su llegada tuvo lugar 
en una fecha doblemente significativa. Por una parte, 2004 marcó el 30 aniversario de la reanudación de las relaciones diplomáticas húngaro-mexicanas, y por la otra, la visita tuvo lugar del 12 al 14 de mayo, es decir, ocurrió menos de dos semanas después de que Hungría se convirtiera en miembro de la Unión Europea. El presidente de México sostuvo pláticas con el primer ministro Péter Medgyessy, y con el presidente Ferenc Mádl. Ese mismo mes Medgyessy, líder político del flamante nuevo miembro de la Unión Europea, viajó a México con el fin de presidir la III cumbre América Latina-UE, en Guadalajara (KM, 2004, p. 59, 68). La adhesión de Hungría a la UE le abrió nuevas puertas hacia los países al sur del Río Bravo.

\section{Nexos en el contexto de la Unión Europea}

Cuando Hungría se adhirió a la integración europea, se hizo parte de su sistema de relaciones y tratados, que significaron oportunidades y obligaciones que Hungría 'heredó' al convertirse en país miembro. Desafortunadamente faltaron conocimientos profundos sobre el potencial de estas posibilidades, ya que en la década de los 1990 y a principios del siglo XXI el liderazgo húngaro había concentrado sus esfuerzos básicamente para cumplir con los criterios de entrada a la UE y convertirse en Estado miembro, concentración que resultó en una carencia de interés no solamente hacia América Latina en sí, sino paradójicamente también hacia el desarrollo de los vínculos entre esa región y la Unión Europea, la organización dentro de la cual planeaba su futuro. Para 2004, los lazos entre la UE y los países latinoamericanos contaban ya con una historia de varias décadas. Para efectos de este escrito, vamos a resumir los compromisos mexicanos, para poder mostrar la red de convenios de la cual Hungría y otros 9 países, se hicieron parte desde principios del nuevo milenio.

\section{Antecedentes: lazos entre México y la Unión Europea anteriores a 2004}

Los nexos entre México y la Comunidad Económica Europea (CEE), -más tarde Comunidades Europeas (CE) y desde 1992 Unión Europea (UE) - se ajustaron con las tendencias latinoamericanas: comenzaron a formarse en los años sesenta poco después del nacimiento de la organización europea, pero el Acuerdo Marco de primera generación fue firmado más tarde, en la década siguiente. Los primeros tratados de este tipo fueron concluidos con Argentina, Brasil y Uruguay entre 1971 y 1974. Con México se hizo en 1975, el mismo año en que el gobierno mexicano firmó un acuerdo de cooperación con el CAME. No obstante, en su totalidad, las relaciones entre México y la CEE/CE fueron muy poco intensas en las décadas de los sesenta y setenta (Sanahuja, 2000, p. 36). 
Los años ochenta trajeron consigo cambios importantes en ambos lados del océano Atlántico, que afectaron las relaciones bilaterales. A nivel regional, en América Latina hay que mencionar la crisis económica a principios de la década, que por una parte contribuyó a la liberalización de las importaciones, y por la otra, a la caída de varios regímenes militares, la llegada de líderes civiles al poder, y el inicio de una transición democrática. Todo esto hizo a la región más atractiva para Europa Occidental. Esto coincidió en tiempo con el crecimiento de la CE hacia el sur, y la incorporación de España y Portugal en 1986. Los dos países llevaron sus prioridades de política exterior a la CE, contribuyendo de esta manera a un incremento de la atención hacia América Latina (Szente-Varga, 2009, pp. 1-14).

El caso particular de México es un poco diferente de las tendencias generales. Hay que recalcar que, de manera similar a otros países latinoamericanos, también abrió sus puertas a los productos extranjeros, pero la apertura económica no fue acompañada por cambios en el terreno político. No se produjo una transformación democrática en el país, el PRI siguió en el poder. Más aún, hubo un fraude electoral en 1988, a través del cual Carlos Salinas de Gortari llegó a la presidencia. El apoyo del PRI iba en declive desde los eventos sangrientos de 1968, la crisis económica de principios de los ochenta y el terremoto de 1985, que dejó en ruinas a la Ciudad de México. El partido hegemónico no gozaba ya del apoyo de la mayor parte de los votantes, pero era todavía suficientemente fuerte para no soltar las riendas del país. La persistencia del PRI en el poder había garantizado hasta entonces la estabilidad por lo que convenía a los intereses geopolíticos de los Estados Unidos - estamos aún en tiempos de la Guerra Fría, y la Comunidad Europea tampoco puso peros.

La Comunidad más bien trató a México a base de consideraciones comerciales y económicas, y sus pasos fueron actos reflejos, en el sentido de no desempeñar un rol pionero o de iniciativa, sino más bien como reacción a fenómenos que podrían tener un efecto negativo en las relaciones bilaterales y/o sobre las posiciones de la propia CE. La organización abrió una representación en la Ciudad de México en 1989, inmediatamente después de las elecciones ya mencionadas. Esta presencia, y la consiguiente intensificación de los contactos estuvo motivada por el inminente Tratado de Libre Comercio de América del Norte (TLCAN), al que México iba a adherirse en unos años más.

En 1991, se firmó un nuevo documento “comercial y de cooperación, [sin] ningún alcance en materia política" (Méndez Escobar, 1996, p. 119): el Acuerdo Marco de Cooperación entre la Comunidad 
Europea y México. "En su momento, este instrumento de colaboración, conocido como de tercera generación, fue el más amplio que la CE hubiera alcanzado con cualquier país latinoamericano" (Chen Charpentier, 1996, p. 156). El Acuerdo fue complementado con protocolos bilaterales concluidos con España en 1990, Francia en 1992, Italia en 1994 y Alemania en 1996 (Velázquez \& Domínguez, 2008, p. 4).

El TLCAN - presentado oficialmente como un paso hacia el primer mundo-, también trajo preocupaciones en el sentido de que podría aumentar aún más la dependencia económica de México respecto a los Estados Unidos. El gobierno mexicano intentó buscar contrapesos. Al estrechar las conexiones bilaterales, la Comunidad Europea, por su parte, trataba de evitar una posición desventajosa en el mercado norteamericano. En 1993, justo antes de que México firmara el TLCAN ( $1^{\circ}$ de enero de 1994), Jacques Delors, a la sazón presidente de la Comisión de las Comunidades Europeas, hizo una visita oficial a México. De vuelta en Europa, en la Cumbre de Copenhague (1993) propuso unos vínculos especiales con este país (Arrieta Munguía, 1996, p. 138).

Después de la firma del TLCAN, México y la Unión Europea emitieron el comunicado Declaración Conjunta Solemne, expresando su deseo de fortalecer sus relaciones. Para México esto pronto se hizo aún más urgente con la llamada "crisis del tequila" que impactó al país a mediados de los años noventa (Pólyi, c. 2004). Aparte del apoyo de los Estados Unidos, el gobierno mexicano intentó conseguir respaldo europeo. El presidente Ernesto Zedillo viajó a Europa en 1996, visitando Italia, el Reino Unido y España, y en 1997 estuvo en Alemania y Francia. Estos encuentros tuvieron sin duda un importante efecto sobre la firma, en 1997, del Acuerdo de Asociación Económica, Concertación Política y Cooperación entre la Unión Europea y México, llamado Acuerdo Global (véase Sanahuja, 2000, pp. 35-62). Esto cubrió las siguientes áreas: diálogo político; comercio; movimientos de capital y pagos; contratación pública, competencia, propiedad intelectual y demás disposiciones relacionadas con el comercio y la cooperación. Con base en los artículos 45 y 46 del citado acuerdo, un Consejo Conjunto constituido por miembros del Consejo de la Unión Europea y de la Comisión Europea, así como por representantes del gobierno mexicano, fue establecido para supervisar la aplicación del acuerdo (Acuerdo de Asociación Económica, Concertación Política y Cooperación, 1997).

A pesar de los esfuerzos anteriores, “entre 1993 y 2000, la participación de la UE en las importaciones mexicanas se redujo de $12.1 \%$ a 8.6\%. Mientras la participación de Estados Unidos en el comercio de México (exportaciones + importaciones) pasaba de $75 \%$ a $80 \%$, la de la UE se reducía de 
9\% a 6\%" (Frontini \& Bonnefoy, 2012, p. 103). Para contrarrestar estas tendencias y fortalecer los vínculos ya existentes, fue firmado un tratado de libre comercio entre las dos partes en 2000. El mismo año entró en vigor el ya mencionado Acuerdo Global (Castro Espinoza, 2003, pp. 893-916).

La transición del milenio fue un período activo en las relaciones México - Unión Europea, y más ampliamente, América Latina - Unión Europea. Se declaró una asociación estratégica birregional en 1999, en el primer encuentro de líderes de la Unión Europea, América Latina y el Caribe, en Rio de Janeiro.

Nosotros los Jefes de Estado y de Gobierno de la Unión Europea y de América Latina y el Caribe, hemos decidido promover y desarrollar nuestras relaciones hacia una asociación estratégica birregional, basada en la profunda herencia cultural que nos une y en la riqueza y diversidad de nuestras respectivas expresiones culturales. Las mismas nos han conferido acentuadas identidades multifacéticas, así como la voluntad de contribuir para la creación de un ambiente internacional que nos permita elevar el bienestar de nuestras sociedades y cumpliendo con el principio del desarrollo sostenible, aprovechando las oportunidades que ofrece un mundo cada vez más globalizado, en un espíritu de igualdad, respeto, alianza y cooperación entre nuestras regiones (Declaración de Río de Janeiro, 1999).

En el documento, que presenta un plan tal vez demasiado ambicioso, figuran 55 prioridades para la acción, relacionados con los ámbitos político, económico, cultural, educativo, científico, tecnológico, social y humano.

\section{Institucionalización de los lazos entre la Unión Europea y América Latina en el siglo XXI}

Hungría no solamente se volvió parte de los compromisos y acuerdos internacionales de la Unión Europea, sino que, a partir de 2004, ya siendo miembro de la organización, también tuvo la posibilidad de participar con la formulación de sus vínculos internacionales. En cuanto a los nexos entre la UE y los países latinoamericanos, los primeros años del siglo XXI fueron bastante activos. Varios canales de comunicación, instituciones y foros fueron establecidos y/o consolidados en dichos años, como la Asamblea Parlamentaria Euro Latinoamericana (EuroLat) y la Fundación Unión Europea-América Latina y el Caribe (Fundación UE-ALC). 
El establecimiento de la Asamblea Parlamentaria Euro Latinoamericana fue decidido en Viena en 2006, en la Cumbre de los Jefes de Estado y de Gobierno UE-ALC. En el encuentro participaron por la parte húngara el primer ministro Ferenc Gyurcsány, el ministro de relaciones exteriores Ferenc Somogyi y tres otros representantes (KM, 2006, p. 42). El objetivo de EuroLat es preparar las Cumbres bianuales y promover la cooperación entre la Unión Europea y América Latina. Está integrada por 150 miembros, 75 de Europa y 75 de América Latina, y está encabezada por dos vicepresidentes, uno de cada región. Cuenta con una sesión plenaria, oficina ejecutiva y un secretariado, así como grupos de trabajo y cuatro comisiones: 1) de asuntos políticos, seguridad y derechos humanos, 2) asuntos económicos, financieros y comerciales, 3) asuntos sociales, jóvenes y niños, intercambios humanos, educación y cultura y 4) desarrollo sostenible, medio ambiente, política energética, investigación, innovación y tecnología (Parlamento Europeo, 2020).

La Fundación Unión Europea-América Latina y el Caribe (Fundación UE-ALC) se estableció en 2010 en la Cumbre UE-ALC de Madrid con el fin de apoyar el acercamiento de las dos partes. El representante húngaro en la reunión fue el ministro de relaciones, Péter Balázs (KM, 2010, pp. 878-79). Comenzó a funcionar en 2011, y a partir de 2019, con la entrada en vigor del acuerdo constitutivo, adquirió carácter de organización internacional. La sede de la organización se encuentra en Hamburgo y cuenta con más de 60 países miembros. Hungría ratificó el acuerdo constitutivo en mayo de 2017, siendo el tercer país europeo en hacerlo, tras Suecia y Finlandia. La ratificación por parte de México tuvo lugar en julio de 2018. El Ministerio de Asuntos Exteriores de Hungría -renombrado en 2014 como Ministerio de Comercio Exterior y de Asuntos Exteriores- firmó un memorándum de cooperación con la organización en septiembre de 2017 y se comprometió a nombrar un embajador de buena voluntad para apoyar la labor de la Fundación. El diplomático Pál Varga-Koritár, quien fue embajador de Hungría en Argentina y en México, así como embajador itinerante en varios países sudamericanos, es el primero en desempeñar esta función (Magyarország kormánya, 2017).

La Cumbre de los Jefes de Estado y de Gobierno celebrada en Río de Janeiro en 1999, y seguida por un encuentro en Madrid en 2002, fue institucionalizada en forma de cumbres bianuales UE-ALC. La reunión de 2004 fue de una importancia especial tanto para México como para Hungría. México fue el país huésped y la ciudad de Guadalajara el sitio de la reunión. Para Hungría, esta resultó ser su primera participación, que además tuvo el honor de presidir el primer ministro húngaro. Después fueron organizadas otras cumbres: en 2006 en Viena, en 2008 en Lima y en 2010 en Madrid. En la década de 
2010 las cumbres UE-ALC fueron reemplazadas por las de UE-CELAC (2013 en Santiago de Chile y 2015 en Bruselas).

La idea de la Comunidad de Estados Latinoamericanos y Caribeños -una organización que agrupara a todos los estados de la región, independientemente de si fueron antiguas colonias españolas, portuguesas, inglesas, francesas, holandesas etc.- nació en México en 2010, en un periodo activo y exitoso del regionalismo latinoamericano. $\mathrm{Su}$ desarrollo fue facilitado por la reducción del interés estadounidense por Latinoamérica tras el final de la Guerra Fría y el desplazamiento del foco de atención de Washington hacia el problema planteado por el islamismo internacional tras los atentados del 11 de septiembre de 2001, lo que dio más espacio de movimiento a las potencias regionales latinoamericanas (Riggirozzi \& Tussie, 2012); pero también por un crecimiento económico regional y la llamada marea rosa. Ambos factores favorecieron la intensificación de los esfuerzos para fortalecer la cooperación e integración regionales. El país motor de la CELAC ha sido México, aunque también hay que mencionar a Venezuela, puesto que la organización se fundó en Caracas en 2011. Por desgracia, para la segunda mitad de la década, tanto la CELAC como otras organizaciones regionales latinoamericanas tuvieron que enfrentarse con serios desafíos (Mijares \& Nolte, 2018, 105-112). Los problemas económicos fueron desalentadores, mientras la crisis en Venezuela y la situación en Nicaragua desunieron a los miembros. La cumbre UE-CELAC propuesta para 2017 en San Salvador tuvo que ser aplazada, y es cuestionable si la cooperación puede continuar en este marco.

Paralelamente a los contactos con la región, la Unión Europea también buscó enlaces con grupos de países y con Estados individuales. Cuando el acercamiento general se complicó, esta última alternativa empezó a cobrar más importancia, como la relación entre la UE y México.

\section{Lazos entre México y la Unión Europea a partir de 2004}

Los cambios políticos que provocaron el final del régimen de partido hegemónico y permitieron la alternancia política afectaron de una manera positiva a la imagen de México en el mundo y posiblemente contribuyeron a la intensificación de los enlaces entre el país y la UE, ya incluyendo a Hungría. Otro factor que hay que mencionar es que el Alto Representante de la Unión para Asuntos Exteriores y Política de Seguridad Común fue Javier Solana entre 1999 y 2009, quien logró incorporar algunas prioridades de la política exterior española a la UE, como la importancia de América Latina (Sánchez Andrés \& Pérez Herrero, 2015, pp. 211-212). Solana visitó México en 2007. Ese mismo año la UE lanzó un documento 
estratégico para México (2007-2013) en el que figuraron los siguientes sectores prioritarios: “1) Cohesión social; 2) Desarrollo económico sostenible y competitividad (especialmente a nivel de pequeñas y medianas empresas -PyMEs-) y 3) Educación y cultura" (CE, 2007, p. 2). El año 2008 trajo consigo la visita de José Manuel Barroso, presidente de la Comisión Europea, así como el comienzo de la asociación estratégica entre la UE y México, que prometía un lugar destacado para este último en los lazos internacionales de la entidad europea. Para efectos de fechas, la asociación se considera establecida en octubre de 2008 (Szente-Varga, 2019, p. 176).

En la comunicación de la Comisión Europea, Hacia una Asociación Estratégica UE-México se hace un resumen de la importancia de México desde un punto de vista europeo. Entre otras cosas, anota:

Uno de los principales activos de México en América Latina es su posición geográfica estratégica en la frontera con los EE.UU. México es un actor político, económico y cultural importante en América Latina y cabe esperar que su papel en la escena mundial vaya ganando preponderancia. Su economía se halla plenamente integrada en el TLCAN y su riqueza cultural confiere peso a su voz en toda América Latina. México constituye un verdadero «puente» cultural, político y físico entre Norteamérica y América Latina y, en cierta medida, también entre los países industrializados y los emergentes. Esa característica es uno de sus principales activos en el contexto de una comunidad internacional cada vez más multilateral y multicultural (CE, 2008, p. 3).

Este papel de vínculo es también subrayado en el análisis de Claudia Franco Hijuelos (2010, pp. 61-62). No obstante, las relaciones entre la UE y México no se desarrollaron tan espectacularmente como se esperaba (Ruano, 2008, pp. 297-329; Ruano, 2013, pp. 619-644).

El comercio y la economía mexicana siguen dependiendo en exceso de Estados Unidos. El tratado con Europa -región que fue superada por China como segundo socio comercial de México- no cambió esa fuerte dependencia porque simplemente no sirvió para diversificar los intercambios comerciales del país con esa próspera parte del mundo, como exponían los discursos oficiales para ganar el apoyo de la opinión pública al tratado. Tampoco generó los empleos y los impactos socioeconómicos prometidos (Appel, 2017). 
Para finales de la segunda mitad de la década de 2010, la Unión Europea es el tercer socio comercial de México, mientras que éste se ubica en decimocuarto lugar como socio comercial de la UE (EEAS, 2016a). Las dos partes llegaron a un nuevo acuerdo comercial en abril de 2018, que formará parte de un nuevo Acuerdo Global.

Amén de los vínculos comerciales y económicos, es menester mencionar la cooperación en áreas como migraciones, seguridad, combate contra las drogas y cambio climático. Éstos y otros temas figuran en el Plan ejecutivo conjunto de la Asociación Estratégica México-Unión Europea (Council of the European Union, 2010).

En resumen, aunque mucho se ha logrado dichos vínculos tienen potencial para más. No solamente las relaciones UE-México dan esta impresión, sino también los acuerdos bilaterales HungríaMéxico. Para terminar, vamos a analizar cómo han cambiado - a partir de la incorporación del país a la Unión Europea (2004) - las prioridades y metas de la política exterior húngara, y cómo figuran en ella América Latina y, en particular, México.

Nexos entre Hungría y México, 2004-2020

Estrategia del Ministerio de Relaciones Exteriores, 2006

La integración de Hungría a la OTAN (1999) y a la Unión Europea (2004) significó que habían sido logradas las metas principales propuestas en tiempos de la transición política y económica a principios de los 1990. Era hora de redefinir los objetivos del país. Una estrategia de relaciones exteriores fue elaborada por el Ministerio en 2006. Su última modificación tuvo lugar en 2008. El documento define a Hungría como "un país europeo de tamaño mediano, integrado fuertemente tanto global como regionalmente, que cuenta con recursos limitados” (1012/2008. (III. 4.) Kormányhatározat, 2018, pp. 1735-1736). Especifica tres orientaciones prioritarias: 1) Hungría competitiva en la Unión Europea, 2) hungaridad exitosa en la región, 3) Hungría responsable en el mundo. En cuanto a los húngaros, especifica tres grupos: los que viven en Hungría, los residentes en los países vecinos, y los de la diáspora, eso es, los emigrados por diversas razones a países más lejanos. El texto afirma que "la base de la cohesión de los húngaros y de la responsabilidad que sienten uno por otro, está brindada por el idioma común y la identidad cultural e histórica." No obstante, las prioridades descritas arriba incluyeron las dos 
primeras categorías (húngaros en Hungría y en la región centroeuropea), pero no la tercera, menos numerosa.

América Latina no aparece en el documento, ni como el hogar de grupos húngaros de la diáspora, ni como una posible alternativa para el comercio internacional. La estrategia señala a los estados miembros de la Unión Europea, los países vecinos, los Estados Unidos y los aliados de la OTAN como los principales socios de Hungría, y por tanto trabaja con un espacio geográfico limitado, que se concentra en Europa y en América del Norte, pero sin incluir a México.

\section{Estrategia del Ministerio de Economía Nacional, 2011}

El Ministerio de Economía Nacional húngaro elaboró en 2011 un documento profesional con el fin de establecer la estrategia de comercio exterior del país para el periodo 2011-2015.

[Hungría fue descrita como] una economía pequeña y abierta, en la que la proporción de la exportación de bienes sobrepasa el $60 \%$ del PIB. Las exportaciones están concentradas en varios aspectos: geográficamente, en cuanto a la estructura de los bienes y en lo referente al tamaño de las empresas exportadoras, todo lo cual significa un serio riesgo (Nemzetgazdasági Minisztérium, 2011, p 3).

El documento ofrece detalles de la situación a fines de la primera década del siglo XXI, por ejemplo: $78 \%$ de las exportaciones y $68 \%$ de las importaciones de Hungría se efectuaban con países de la Unión Europea; el socio comercial más importante era Alemania; y en cuanto a los bienes comercializados, resume que un $30 \%$ de la exportación húngara estuvo compuesta por cinco grupos de productos: teléfonos móviles, aparatos de televisión, automóviles, repuestos de coches y medicamentos.

La citada estrategia incluye algunas referencias latinoamericanas. Se menciona a Brasil, como miembro del grupo BRICS, así como al Mercosur. El texto vislumbra la región latinoamericana como una oportunidad de mediano plazo para que los proveedores húngaros pudieran participar en las crecientes exportaciones de los países europeos desarrollados hacia América Latina, Asia y los países árabes (Nemzetgazdasági Minisztérium, 2011, p. 24).

\section{Estrategia del Ministerio de Relaciones Exteriores, 2011}


El Ministerio de Relaciones Exteriores también elaboró una estrategia en 2011, que lleva como título: Política exterior húngara tras haber ocupado Hungría la presidencia rotativa de la Unión Europea. El documento subraya la necesidad de armonizar valores e intereses. Indica las siguientes prioridades: 1) política regional; 2) orientación euro-atlántica, más precisamente, gestión de los intereses nacionales en la Unión Europea y en la OTAN, y 3) apertura global.

[Este último inciso] en sentido geográfico significa que tanto en los marcos multilaterales como en los bilaterales deseamos buscar posibilidades de cooperación mutuamente ventajosas con aquellos estados con los que nuestros enlaces se vieron eclipsados en las últimas dos décadas, o nuestros lazos anteriores no habían sido suficientemente intensos. Por otro lado, en el sentido temático, la atención global implica nuestro interés hacia cuestiones que aparentemente no afectan de manera directa nuestra patria, pero son problemas importantes de orden internacional (por ejemplo, el terrorismo, la alimentación, la salud mundial, la condición ecológica de los mares) (KM, 2011, p. 36-37).

La estrategia maneja cinco regiones en el capítulo de la apertura global, en orden: región postsoviética; Asia; Cercano Oriente y África del Norte; África subsahariana y el Sahel, y América Latina. Esta última está caracterizada como una región con creciente poder económico y peso político en el mundo, "de importancia destacada para nuestro socio, los Estados Unidos", de mucha relevancia para la Unión Europea, así como hogar de unos 150 mil-200 mil húngaros, miembros de la diáspora.

Existen diferentes estimaciones en cuanto al número de húngaros en las Américas, dependiendo del concepto que se use para definir a los miembros de la diáspora, y de los objetivos de los escritos. En los 1960 y 1970 se estimó que unos 100,000-120,000 húngaros vivían en Brasil; 40,000-70,000 en Argentina; 5,000-8,000 en Uruguay; 3,000-5,000 en México; 2,000-4,000 en Venezuela y unos 20,00025,000 en el resto de los países de la región. En total: “200,000-240,000 húngaros residían en América Latina" (Anderle, 2010, p. 172). Puesto que la gran mayoría llegaron antes de 1950, y no hubo nuevas llegadas, los números han ido decreciendo con el paso de los años. Una estimación reciente calcula con 125,000 húngaros en América del Sur (Miniszterelnökség, 2016, p. 30).

La estrategia afirma que la presencia diplomática se ha debilitado peligrosamente en la región “con base en consideraciones de ahorro no siempre debidamente reflexionadas". Añade que Hungría 
cuenta únicamente con cuatro embajadas en América Latina. "Comprobante doloroso de nuestra falta de presencia en la región es que la proporción de todo el continente no llega al $0.5 \%$ de nuestro comercio exterior” (KM, 2011,pp. 47-48). El 'retiro' de la región afectó negativamente a la diáspora húngara, sus nexos con Hungría, y en general, los lazos húngaro-latinoamericanos, tanto políticos como económicos y culturales.

\section{3.- MÉTODO}

\section{Diseño}

Se han utilizado métodos mixtos para el análisis, principalmente cualitativo (análisis de textos) y, en menor medida cuantitativo (datos estadísticos). Los cambios entre enfoques bilaterales y multilaterales permiten exponer más claramente las conexiones e interdependencias existentes entre los diferentes niveles (nacional, regional, continental, supranacional) de dicha red de relaciones.

\section{Instrumentos}

Puesto que el estudio trata una época reciente, el acceso a materiales de archivo es limitado. Consecuentemente, la investigación se basa principalmente en documentos relacionados con la política exterior de Hungría (anuario del ministerio de relaciones exteriores, estrategias y noticias), comunicados de la Unión Europea y fuentes de prensa, complementados con ensayos académicos, de ambos lados del océano.

\section{Procedimientos}

La perspectiva desde la cual se presentan los vínculos húngaro-mexicanos es la húngara, como lo muestra el mismo título del ensayo, que es además una alusión a uno de los libros del destacado latinoamericanista Ádám Anderle (1943-2016), La mirada húngara, publicado hace una década.

\section{4.- RESULTADOS}

Los vínculos comerciales crecieron después de la crisis de 2009, en parte porque la mitad inicial de la segunda década del siglo marcó un periodo de tendencias de crecimiento económico tanto para América Latina como para Hungría. Porcentualmente el aumento fue espectacular, puesto que los valores originales resultaron bastante bajos. En este sentido, se señala que "entre 2010 y 2013 las exportaciones 
latinoamericanas hacia Hungría crecieron 57\%, mientras las exportaciones húngaras hacia la región aumentaron $73 \%$. Hay que destacar a México, dado que más de 50\% de nuestro comercio con la región (incluyendo exportaciones e importaciones) se desarrolló con este país” (Kormányportál, 2014).

México es el socio comercial número dos de Hungría en el continente americano, detrás de los Estados Unidos, pero antecediendo a Canadá y Brasil. Las exportaciones húngaras a México en 2017 sumaron el $1.1 \%$ de todas las exportaciones de Hungría. Al mismo tiempo Hungría fue el destino de un $0.058 \%$ de las exportaciones de México (OEC, 2017). Ver tabla 1.

Tabla 1.

Comercio exterior de Hungría, 2018

\begin{tabular}{lccccc}
\hline & E.E.U.U. & México & Canadá & Brasil & Argentina \\
\hline$\%$ de exportaciones húngaras dirigidas a & 3.19 & 0.82 & 0.35 & 0.24 & 0.23 \\
$\%$ de importaciones húngaras provenientes de & 1.65 & 0.23 & 0.07 & 0.14 & 0.01 \\
\hline
\end{tabular}

Fuente: OEC, Hungary, country profile, (2018).

El comercio exterior de Hungría sigue estando muy concentrado en Europa. El 82\% de las exportaciones y 83\% de las importaciones húngaras en 2017 se ubicaron en el viejo continente. Los datos relativos a las Américas fueron muy modestos: 2.5\% (América del Norte) y $0.269 \%$ (América del Sur), en cuanto a las exportaciones, e importaciones de $5.6 \%$ y $0.96 \%$, respectivamente.

\section{Una nueva estrategia: apertura hacia el sur}

Dadas las circunstancias arriba descritas, desde marzo de 2015, el ministro de Asuntos Exteriores y Comercio Exterior, Péter Szijjártó, propuso al primer ministro Viktor Orbán la estrategia de la apertura hacia el sur, un acercamiento enfocado hacia África y América Latina (MTI, 2015). Unos días después, Szijjártó inauguró solemnemente la Casa Húngara de Comercio en la capital mexicana (SRE, 2015). Esta visita oficial de 2015 rompió un 'silencio' de más de 20 años, ya que como se ha señalado, la última vez que un ministro húngaro de Relaciones Exteriores hizo una visita oficial a México fue en 1992, específicamente la de Géza Jeszenszky. Szijjártó tuvo reuniones con varios funcionarios mexicanos, y también solicitó el ingreso de Hungría a la Alianza del Pacífico, en calidad de observador. Esto se materializó en el verano de 2015. Tres años después, bajo la organización de la presidencia rotativa húngara en el Grupo de Visegrád, tuvo lugar el 5 de junio de 2018 un primer encuentro entre la Alianza y el Grupo (Magyarország kormánya, 2018). 
La apertura hacia el sur significó más atención hacia América Latina, hacia las organizaciones regionales, como la Alianza del Pacífico (González Ayala, 2020), y paralelamente con esto un empeño en aumentar la presencia diplomática en la región, o mejor dicho, en recuperarla. Para finales de 2010 solamente había embajadas húngaras en Argentina, Brasil, México y Cuba. Todas llevaban concurrencias. Las más atareadas fueron con toda seguridad las embajadas en Buenos Aires (que llevaba las con concurrencias en Uruguay, Paraguay, Chile, Bolivia, Perú y Ecuador), y en la Ciudad de México (que atendía también Guatemala, El Salvador, Honduras, Costa Rica y Jamaica). En lo referente a los demás países del istmo, la embajada en Cuba se encargó de ellos (Nicaragua y Panamá), así como de la República Dominicana.

El gobierno húngaro reabrió embajadas en cuatro países: Colombia, Chile, Ecuador y Perú. Así, el número de embajadas se duplicó, y actualmente (2020) son ocho (Argentina, Brasil, México, Cuba, Colombia, Chile, Ecuador y Perú). La representación en la Ciudad de México sin embargo sigue manejando muchas concurrencias: Belice, Guatemala, El Salvador, Honduras, Nicaragua y Costa Rica. El trabajo de las embajadas es apoyado por una red de consulados honorarios que ha sido expandida en el siglo XXI. En México en 2020 funcionan 4 consulados honorarios húngaros, en Cancún, Chihuahua, Guadalajara y Monterrey. La persona encargada de mantener el contacto del gobierno con los cónsules honorarios de Hungría en el mundo, es un comisario ministerial.

En los temas bilaterales húngaro-mexicanos del siglo XXI hay un énfasis sobre los contactos comerciales, si bien eso no significa que éste sea el único campo de cooperación. En 2017 México ocupó el decimotercer lugar en el mundo tanto entre los países exportadores como importadores, mientras Hungría figuró en los lugares 34 y 33 respectivamente. El aumento anual del flujo de los productos fue de entre 8 y 14\%, siendo este último número un indicador del creciente sector de las importaciones húngaras (WTO, 2018, p. 124). La inversión mexicana acumulada en Hungría se estimó en 2,015.5 millones de dólares en 2018. El comercio bilateral ascendió a 1,475.6 millones de dólares (SRE, 2019). Gábor Kun, subdirector general de la Casa Nacional de Comercio de Hungría declaró: "Vemos excelentes oportunidades de negocios en la industria alimenticia, en especial en los alimentos gourmet, en la tecnología médica, en la industria farmacéutica, en las energías renovables y en la gestión del agua" (SRE, 2015).

La política exterior húngara considera a México como “el pilar más importante de la presencia húngara en América Latina”, que "ocupa el primer lugar en el sistema de relaciones húngaras con la 
región” (MTI, 2017). En 2019 el ministro Péter Szijjártó volvió a México, principalmente para abordar cuestiones económicas. Al mismo tiempo se comprometió a que Hungría financiaría la restauración del Ex-Convento de Tepoztlán, Morelos, sitio Unesco desde 1994, y de la Iglesia del Sagrado Corazón de Jesús, en la Ciudad de México - ubicada en la Calle Roma 14, esquina con Londres-, ambos dañados por los sismos de 2017 (SRE, 2019). Esta última tiene un lazo particular con Hungría, puesto que fue conocida como la iglesia de la colonia húngara [en México], y está en la plaza anteriormente denominada Hungría (Torbágyi, 2004, p. 271). La iglesia ostenta siete vitrales decorados con imágenes de santas y santos húngaros, acompañados con breves descripciones sobre sus vidas. Figuran San Martín Caballero; San Emerico; San Ladislao de Hungría; Santa Piroska (Irene); Santa Margarita; Santa Isabel y San Esteban de Hungría (Szente-Varga, 2017, pp. 115-116). Estas conexiones culturales no solamente son interesantes, sino que pueden servir como puentes, puntos de referencia y de experiencia en común, contribuyendo a una base de confianza y de mejor entendimiento que apoyará los acercamientos actuales en todos los campos.

\section{5.- CONCLUSIONES}

Las relaciones diplomáticas entre México y Hungría fueron reanudadas en 1974, y Hungría ha mantenido una embajada en la Ciudad de México desde 1975. Aparentemente existió una buena oportunidad para intensificar los nexos con el final de la Guerra Fría y del manejo de las relaciones internacionales a base de consideraciones ideológicas. Sin embargo, los gobiernos húngaros de la época postsocialista se enfocaron en Europa, ya que una de sus metas principales era convertirse en Estado miembro de la Unión Europea. Esto, aunado a la crisis económica que sacudió al país, relegó a América Latina (junto con México) a segundo - ¿o tercer? - plano, contribuyendo al cierre de embajadas y a la pérdida de presencia húngara en la región.

La adhesión de Hungría a la Unión Europea en 2004 trajo consigo cambios importantes. Por una parte, Hungría se hizo partícipe de los acuerdos internacionales entre la UE y Latinoamérica ya existentes anteriormente -incluyendo contar con América Latina como socio estratégico desde 1999- adquiriendo igualmente obligaciones y oportunidades. Por otra, obtuvo la posibilidad de formar parte directamente de dichos nexos a partir de 2004, ya como Estado miembro. Esta posibilidad no fue aprovechada debidamente, puesto que la adhesión a la UE fue seguida por un aprendizaje interno ya en la Unión, que podemos dar por terminado al asumir Hungría la presidencia rotativa de la UE en 2011. 
Al mismo tiempo el desarrollo de los lazos entre América Latina y la Unión Europea comenzó a perder su ímpetu original. De hecho, el rol de la UE como socio comercial de la región ha estado decreciendo en los últimos años. A pesar de los obvios avances, es de notar que la Unión Europea se caracterizó a sí misma en el comunicado Una asociación reforzada entre la Unión Europea y América Latina como "el primer socio comercial de numerosos países, en particular los del Mercosur” (CE, 2005), cuatro años más tarde como el "segundo socio comercial más importante de América Latina" (CE, 2009) y en 2019 como “el tercer socio comercial más importante de América Latina y el Caribe” (EEAS, 2019). La pérdida de posición de la UE es evidente: en el transcurso de una década y media pasó del primero y segundo lugares al tercero. Su debilitamiento en la región se debe a varios factores, algunos externos como la competencia china; otros internos, como la desaceleración del regionalismo latinoamericano, los desafíos económicos de la región, la polarización política y los conflictos no resueltos que hacen a América Latina menos atractiva para la inversión exterior, así como procesos de la propia UE que disminuyeron el interés por América Latina, como por ejemplo las ampliaciones de la organización en 2004 y 2007, la crisis financiera de 2008 y la crisis europea de migración de 2015. En el documento de la estrategia global para la política exterior y de seguridad de la Unión Europea, titulado Una visión común, una actuación conjunta: una Europa más fuerte, América Latina es mencionada solamente dos veces. Aparece en un solo párrafo como parte de la región del Atlántico. Es de notarse también que en lo referente a países, figuran Cuba y Colombia, mientras los socios estratégicos, como México, quedan sin mención (EEAS, 2016b).

No obstante, es posible volver a estrechar nexos. Funciona en este contexto la nueva estrategia de asuntos exteriores llamada la apertura hacia el sur, lanzada por el gobierno húngaro, para recuperar y reforzar lazos. Es verdad que en Hungría ha habido más atención e interés hacia México que viceversa. Podemos decir que es natural debido al tamaño de la población, del territorio, etc. Es cuestión de escala. Los gobiernos mexicanos por lo general se interesaron no en países individuales de Europa Central / Oriental, sino en entidades más grandes. Los contactos por ejemplo fueron bastante intensos con la Monarquía Dual Austro-húngara entre 1901, la reanudación de las relaciones, y 1914, principios de la primera guerra mundial (Szente-Varga, 2017, pp. 23-39). Décadas más tarde, ya en la Guerra Fría, hubo acercamientos entre México y el CAME (Lara, 1978, pp. 63-70; Cerda Dueñas, 2019, pp. 195-214). Basándonos en las experiencias del pasado, se puede recomendar que paralelamente con los esfuerzos bilaterales, Hungría debe buscar las oportunidades para actuar como parte de unidades más grandes y 
potentes, como la Unión Europea o bien, dentro de ella, el Grupo de Visegrád, para aproximarse a México.

En cuanto a las investigaciones, un posible desarrollo en el futuro sería la elaboración de estudios de caso sobre relaciones bilaterales entre países centroeuropeos y México, utilizando la misma metodología y temática, con el fin de facilitar comparaciones. Como siguiente paso, es deseable contar con estudios comprehensivos acerca de los nexos entre México y la región de Europa Central, con la colaboración de varios especialistas, a efecto de traspasar las perspectivas nacionales.

\section{REFERENCIAS}

AHGE-SREM / Archivo Histórico Genaro Estada - Secretaría de las Relaciones Exteriores de México. (1998). Informe de la EMBAMEX en Budapest, III-10075-3.

AHGE-SREM. (1992a). Informe de la EMBAMEX en Budapest, III-4860-2, marzo.

AHGE-SREM. (1992b). Informes de la EMBAMEX en Budapest, III-4860-2, 31 de julio y 3 de agosto. 1012/2008. (III. 4.) Korm. határozat. Magyarország külkapcsolati stratégiájáról [Decreto gubernativo 1012/2008 de 4 de marzo de 2008 sobre la estrategia de relaciones exteriores de Hungría]. (2008). Magyar Közlöny, 36, 1732-1744.

Acuerdo de Asociación Económica, Concertación Política y Cooperación entre la Comunidad Europea y sus estados miembros, por una parte, y los Estados Unidos Mexicanos, por otra, 1997. https://eeas.europa.eu/sites/eeas/files/acuerdo97_es_1.pdf

Archivo Histórico Diplomático Mexicano. (1989). Relaciones México Polonia 1921/1989. Cronología y documentos. SRE.

Anderle, Á. (2010). La mirada húngara. Estudios históricos sobre España y América Latina. SZTE.

Appel, M. (2017, 17 febrero). Trump, México y la Unión Europea. Proceso. https://www.proceso.com.mx/474080/trump-mexico-la-union-europea

Arrieta Munguía, J. (1996). La política exterior de México hacia la Unión Europea, 1990-1995. Revista Mexicana de Política Exterior, 49, 123-148.

Castro Espinoza, Á. (2003). Tan lejos de Europa y tan cerca de los Estados Unidos. Orígenes, negociación y perspectivas del acuerdo político y comercial entre México y la Unión Europea. Foro Internacional, 43(4), 893-916. 
Chen Charpentier, J. (1996). Las relaciones entre México y Europa hoy. Revista Mexicana de Política Exterior, 49, 149-158.

CE [Comisión Europea]. (2005). Una asociación reforzada entre la Unión Europea y América Latina. COM (2005) 636 final.

CE [Comisión Europea]. (2007). Mexico Country Strategy Paper 2007-2013. E/2007/1063.

CE [Comisión Europea]. (2008). Hacia una Asociación Estratégica UE-México. COM (2008) 447 final.

CE [Comisión Europea]. (2009). La Unión Europea y América Latina: Una asociación de actores globales. COM (2009) 495 final.

Cerda Dueñas, C. (2019). Cooperación en la turbulencia bipolar: México y el Consejo de Ayuda Mutua Económica, CIDOB d'Afers Internacionals, 120, 195-214. https://doi.org/10.24241/ /rcai.2018.120.3.195

Council of the European Union. (2010). Mexico - European Union Strategic Partnership Joint Executive Plan, 9820/10 (Presse 126).

Declaración de Río de Janeiro. (1999). https://www.oei.es/historico/cumbrerio.htm

EEAS. (2016a). México y la UE, Delegación de la Unión Europea en México. https://eeas.europa.eu/delegations/mexico_es/1528/M\%C3\%A9xico\%20y\%20la\%20UE

EEAS. (2016b). Una visión común, una actuación conjunta: una Europa más fuerte. Estrategia global para la política exterior $y$ de seguridad de la Unión Europea. http://eeas.europa.eu/archives/docs/top_stories/pdf/eugs_es_.pdf

EEAS. (2019). La Unión Europea, América Latina y el Caribe: aunar fuerzas para un futuro común. Comunicación conjunta al Parlamento Europeo y al Consejo. https://eeas.europa.eu/sites/eeas/files/eu-lac_communication_es.pdf

Franco Hijuelos, C. (2010). La Asociación Estratégica México-Unión Europea: origen y perspectivas. Revista Mexicana de Política Exterior, 89(2), 57-82.

Frontini, G., \& Bonnefoy, P. (2012). Relaciones comerciales entre la UE y México. In G. Solana González (Ed.), México: un destino natural y estratégico (pp. 101-120). Universidad Nebrija.

Gazdag. F. (Ed.) (2014). A magyar külpolitika, 1989-2014 [Política exterior húngara, 1989-2014]. Nemzeti Közszolgálati Egyetem.

Gazdag, F, \& Kiss J. L. (2017). A magyar külpolitika negyedszázada (1990-2016) [Un quarto de siglo de la política exterior húngara]. Dialóg Campus.

González Ayala, F. R. (2020). La Alianza del Pacífico y la hegemonía de China y Estados Unidos. Política, Globalidad y Ciudadanía, 6(12), 170-187. https://doi.org/10.29105/pgc6.12-9 
Hogan, M., \& Paterson, T. G. (2004). Explaining the History of American Foreign Relations $\left(2^{\mathrm{da}}\right.$ edición). Cambridge University Press.

Kormányportál. (2014, 6 de mayo). Latin-amerikai kötelék [Enlaces latinoamericanos]. http://accessibility.government.hu/hu/kulugyminiszterium/biztonsagpolitikaert-feleloshelyettes-allamtitkarsag/beszedek-publikaciok-interjuk/latin-amerikai-kotelek

KM [Külügyminisztérium]. (1990-2010). Magyar Külpolitikai Évkönyv [Anuario de la Política Exterior Húngara]. Kossuth.

KM [Külügyminisztérium]. (2011). Magyar külpolitika az uniós elnökség után [Política exterior húngara tras haber ocupado Hungría la presidencia rotativa de la Unión Europea]. https://brexit.kormany.hu/download/4/c6/20000/kulpolitikai_strategia_20111219.pdf

Lara, P. (1978). Mexikó gazdasági együttműködése a KGST országokkal [Cooperación de México con los países del CAME], Külgazdaság, 22(9), 63-70.

Magyarország kormánya. (2017, 13 de septiembre). Új együttmüködési forma a Külgazdasági és Külügyminisztérium és az EU-LAC Nemzetközi Alapítvány között [Una nueva forma de cooperación entre el Ministerio de Comercio Exterior y de Asuntos Exteriores de Hungría y la Fundación internacional EU-LAC]. https://www.kormany.hu/hu/kulgazdasagi-eskulugyminiszterium/gazdasagdiplomaciaert-felelos-allamtitkar/hirek/uj-egyuttmukodesi-formaa-kulgazdasagi-es-kulugyminiszterium-es-a-z-eu-lac-nemzetkozi-alapitvany-kozott

Magyarország kormánya. (2018, 6 de junio). A Visegrádi Csoport új partnerekkel bővíti kapcsolatait: együttmüködés indult a V4 és a latin-amerikai Csendes-óceáni Szövetség között” [El grupo de Visegrád amplia sus contactos: cooperación entre el grupo V4 y la Alianza del Pacífico]. https://www.kormany.hu/hu/kulgazdasagi-es-kulugyminiszterium/gazdasagdiplomaciaertfelelos-allamtitkar/hirek/a-visegradi-csoport-uj-partnerekkel-boviti-kapcsolataitegyuttmukodes-indult-a-v4-es-a-latin-amerikai-csendes-oceani-szovetseg-kozott

Méndez Escobar, F. (1996). La política de la Unión Europea hacia América Latina: el caso de México. Revista Mexicana de Política Exterior, 49, 91-122.

Mijares, V. M., \& Nolte, D. (2018). Regionalismo posthegemónico en crisis. Foreign Affairs Latinoamérica, 18(3), 105-112.

Miniszterelnökség (2016). Magyar diaszpórapolitika [Política húngara de diáspora]. Nemzetpolitikai Államtitkárság. 
MTI [Magyar Távirati Iroda]. (2015, 5 de marzo) Szijjártó meghirdette a déli nyitás stratégiáját [Szijjártó anunció la estrategia de apertura hacia el sur]. https://www.origo.hu/itthon/20150305-szijjartopeter-meghirdette-a-deli-nyitas-strategiajat.html

MTI [Magyar Távirati Iroda]. (2017, 16 de noviembre). Mexikó Magyarország latin-amerikai jelenlétének legfontosabb pillére [México es el pilar más importante de la presencia húngara en América Latina]. kormany.hu/hu/kulgazdasagi-es-kulugyminiszterium/gazdasagdiplomaciaertfelelos-allamtitkar/hirek/mexiko-magyarorszag-latin-amerikai-jelenletenek-legfontosabb-pillere Nemzetgazdasági Minisztérium. (2011). Külgazdasági stratégia [Estrategia de comercio exterior]. https://2010-2014.kormany.hu/download/1/d7/30000/kulgazdasagi_strategia.pdf

OEC. (2018). Hungary, country profile. https://oec.world/en/profile/country/hun

Opatrný, J. (2011). Las relaciones checo-mexicanas. Editorial Karolinum.

Parlamento Europeo. (2020).

EuroLat.

https://www.europarl.europa.eu/intcoop/eurolat/presidency_and_bureau/default_es.htm

Pólyi, Cs. (c. 2004). Mexikó és az Európai Unió intézményes kapcsolatai: eredmények és kihasználatlan lehetőségek [Las relaciones institucionales de México y la Unión Europea: resultados y posibilidades desaprovechadas]. http://www.publikon.hu/application/essay/95_1.pdf

Riggirozzi, P., \& Tussie, D. (Ed.). (2012). The Rise of Post-Hegemonic Regionalism. The Case of Latin America. Springer.

Romsics, I. (1999). Magyarország története a XX. században [Historia de Hungría en el siglo XX]. Osiris.

Ruano, L. (2008). De la exaltación al tedio: las relaciones entre México y la Unión Europea durante el sexenio de Vicente Fox. Foro Internacional, 48(1-2), 297-329.

Ruano, L. (2013). Inercia institucional en un ambiente difícil: las relaciones de México con Europa durante la administración de Felipe Calderón, 2006-2012. Foro Internacional, 53(3-4), 619-644.

Sanahuja, J. A. (2000). Trade, Politics, and Democratization: The 1997 Global Agreement between the European Union and Mexico. Journal of Interamerican Studies and World Affairs, 42(2), 35-62.

Sánchez Andrés, A., \& Pérez Herrero, P. (2015). Historia de las relaciones entre España y México, 1821 2015. Marcial Pons.

SRE. (2015, 27 de marzo). Péter Szijjártó inauguró la casa húngara de comercio en Ciudad de México. https://embamex.sre.gob.mx/hungria/index.php/es/noticias/7-noticias-de-mexico/236-peterszijjarto-inauguro-la-casa-hungara-de-comercio-en-ciudad-de-mexico 
SRE. (2019, 10 de abril). Recibe el canciller Marcelo Ebrard al ministro de Asuntos Exteriores y Comercio Exterior de Hungría, Péter Szijjártó. Comunicado 081. https://www.gob.mx/sre/prensa/recibe-el-canciller-marcelo-ebrard-al-ministro-de-asuntosexteriores-y-comercio-exterior-de-hungria-peter-szijjarto?state=published

Szente-Varga, M. (2009). Az Európai Unió és Mexikó: Ki nevet a végén?” [La Unión Europea y Hungría]. Kül-Világ, 6(4), 1-14.

Szente-Varga, M. (2017). El baúl de las nomeolvides. Dialóg Campus.

Szente-Varga, M. (2018). Relaciones húngaro-nicaragüenses en la década de los 1980. Relaciones internacionales: 56. ${ }^{\circ}$ Congreso Internacional de Americanistas (pp. 78-86). Universidad de Salamanca.

Szente-Varga, M. (2019). Bilateral and Regional Relations of the EU with Mexico, Central America and the Caribbean. In A. Molnár \& Z. Gálik (comps.), Regional and Bilateral Relations of The European Union (pp. 169-183). Dialóg Campus.

Torbágyi, P. (2004). Magyarok Latin-Amerikában [Húngaros en América Latina]. A Magyar Nyelv és Kultúra Nemzetközi Társasága.

Velázquez, R., \& Domínguez, R. (2008). Relaciones México-Unión Europea: una evaluación general en el sexenio del presidente Vicente Fox. Centro de Investigación y Docencia Económicas.

WTO. (2018). A6. Leading exporters and importers in world merchandise trade, 2017. World Trade Statistical Review, 124. 